\title{
Lo múltiple como lo opuesto a lo uno 1
}

\author{
ANTONIO MILLÁN-PUELLES \\ Universidad Complutense de Madrid
}

«LO UNO Y LO MÚLTIPLE SE OPONEN -dice Aristóteles-- de varias maneras, entre las cuales está la que opone lo uno, en tanto que indivisible, a lo múltiple, en tanto que divisible. Porque a lo dividido o divisible se le da el nombre de múltiple, $\mathrm{y}$ a lo indivisible o indiviso se le denomina uno. Dado que hay cuatro clases de oposición, y uno de esos dos términos ${ }^{2} \operatorname{comporta}_{\text {privación, habrá }}$ entre ello una oposición de contrarios, no de contradictorios ni de relativos» 3 .

En el comentario aquinatense leemos: «habiendo dicho 4 que lo uno y lo múltiple se oponen como lo indivisible y lo divisible, los cuales se ve que son opuestos según el modo de la privación y la posesión, concluye, no obstante, que lo uno y lo múltiple se oponen como contrarios. (...). Porque uno de ellos es según privación, aunque no privación pura. En efecto, así no participaría de la naturaleza del género, y el estar en el mismo género atañe a los contrarios. Es preciso, por tanto, que cada uno de ellos sea una cierta naturaleza de género, aunque uno de los dos participe del género con cierta deficiencia, tal como lo negro se comporta respecto de lo blanco (...). Así, pues, ya que lo uno no significa privación pura, dado que no significa la misma indivisión, sino el mismo ente indiviso, es evidente que lo uno y lo múltiple no se oponen como la privación pura y la posesión, sino como contrarios»5.

1 Fragmento de la segunda parte de La lógica de los conceptos metafísicos (en preparación), cuyo primer volumen vio la luz en la editorial Rialp, Madrid, en 2002.

2 Se refiere a lo uno y lo múltiple.

3 ARISTÓTELES, Metafísica, 1054 a 20-26.

4 Aristóteles.

5 «Cum dixerit quod unum et multitudo opponuntur ut indivisibile et divisibile, quae videntur opponi secundum privationem et habitum, concludit tamen quod unum et multitudo 
La clave de este argumento está en la tesis de que lo uno no es la indivisión, sino lo indiviso, el ente no dividido. En cuanto ente, lo indiviso no es pura privación, por más que se comporte a la manera del portador o sujeto de un cierto defecto o falta: la carencia de división. ¿Pero es, en verdad, este defecto una carencia auténtica? Ello habría de exigir que la división fuese una verdadera perfección, algo auténticamente positivo, y en verdad no lo es 6 , aunque la podamos concebir como si en efecto lo fuese; y así es como la pensamos (conceptualmente, no de un modo judicativo) como algo de lo cual lo uno -lo indiviso- está privado.

Mas tampoco lo múltiple se comporta respecto de lo uno como respecto de la pura carencia de unidad se comporta el sujeto de esta pura carencia. Porque lo múltiple tiene una cierta unidad: de lo contrario, no podría ser ente en forma alguna, siendo así que ser múltiple es, por el contrario, una de las formas de ser ente (aunque no, claro está, una de las formas de ser un único ente). Lo múltiple está afectado por una cabal carencia de unicidad, pero no por una completa falta de unidad.

Por todo ello resulta necesariamente sorprendente la tesis, mantenida por Sto. Tomás en otro lugar, según la cual lo uno que con el ente es convertible (no lo uno que se comporta con el número como la medida con lo medido) se opone, con oposición privativa, a lo múltiple (en cuanto tal): «Lo uno que es principio del número se opone a lo múltiple que es el número como se opone la medida a lo medido, porque lo uno tiene la índole de la medida primera, y el número es pluralidad medida por lo uno. (...) Mas lo uno que se convierte con el ente se opone, con oposición privativa, a lo múltiple, tal como lo indiviso se opone a lo dividido»7. O también: «hay dos modalidades de lo uno. La primera es la de lo uno que se convierte con el ente, (...) y ese uno priva de la multiplicidad en tanto que ésta es causada por la división, aunque no priva de la multi-

opponuntur ut contraria. Oppositio enim quae est secundum privationem et habitum, est principium oppositionis quae est secundum contrarietatem. (...). Alterum enim contrariorum semper est privatio, sed non privatio pura. Sic enim non participaretur naturam generis, cum contraria sint natura quaedam, licet alterum eorum participet naturam generis cum quodam defectu, sicut nigrum se habet ad album. (...) Quia igitur unum non significat privationem puram, non enim significat ipsam indivisionem, sed ipsum ens indivisum, manifestum est quod unum et multitudo non opponuntur secundum privationem puram et habitum, sed sicut contraria», In Met., n. 1986.

6 Aquí el término «división» está tomado de una manera formal, i.e., no en el sentido propio de la eficiencia de una acción de separar o dividir.

7 «unum quod est principium numeri opponitur multitudini, quae est numerus, ut mensura mensurato: unum enim habet rationem primae mensurae, et numerus est multitudo mensurata per unum (...). Unum vero quod convertitur cum ente, opponitur multitudini per modum privationis, ut indivisum diviso», Sum. Theol. I, q. 11, a. 2. 
plicidad intrínseca, que se opone a la unidad. (...) La otra modalidad de lo uno es aquella según la cual éste es principio del número y que añade la índole de ente la de la medida, y de este tipo de lo uno es privación lo múltiple, porque el número resulta de la división de lo continuo»8.

Según J. A. Aertsen, es insatisfactoria la manera en que así se determina la oposición entre lo uno (en sentido trascendental) y lo múltiple: «La determinación que Tomás hace de la oposición entre lo uno trascendental y lo múltiple es insatisfactoria por varias razones. En primer lugar, una privación significa siempre una falta. Pero la unidad no puede expresar un defecto, porque la falta de unidad es falta de ser (...). En segundo lugar, el propio Tomás pone de relieve que la unidad no excluye la multiplicidad, sino la división, y que las nociones de la multiplicidad y la división no son idénticas»9.

La segunda de las razones alegadas por J. A. Aertsen apoyándose en la tesis, que el propio Aquinas mantiene, según la cual la unidad no excluye la multiplicidad, sino la división, debe ser matizada en virtud de lo que se dice en De Potentia, q. 3, a. 16 ad 3 -texto no mencionado aquí por Aertsen-donde se distingue, como hemos visto, entre la multitud extrínseca y la intrínseca. La multitud excluida por la unidad es la segunda, no la primera. En la unidad, oponerse a la división es tanto como oponerse a la multitud intrínseca, no a la extrínseca. Ello no obstante, acierta Aertsen al rechazar que la oposición entre lo uno y lo múltiple sea de carácter privativo; acierta si la privación es entendida como privación estrictamente dicha o pura. Pues la privación pura o estrictamente dicha se caracteriza no tan sólo por darse en un cierto sujeto o poseedor, sino también por otras dos notas: que ese sujeto sea apto para ser excluido por la privación y que, por tanto, la carencia de ello sea sólo eventual, contingente (en tanto que no exigida de una manera esencial).

El texto aristotélico de Met. 1054 a 20-26, ya incluido al comienzo de este escrito, contiene la advertencia de que la oposición entre lo uno y lo múltiple

8 «duplex est unum; quoddam scilicet quod convertitur cum ente (...), et hoc unum privat multitudinem, in quantum multitudo ex divisione causatur ; non quidem multitudinem extrinsecam quam unum constituit sicut pars ; sed multitudinem intrinsecam quae unitati opponitur (...). Aliud vero unum est quod est principium numeri, quod supra rationem entis addit mensurationem; et huius unius multitudo est privatio, quia numerus fit per divisionen continui», De Potentia, q. 3 , a. 16, ad 3).

9 «Thoma's determination of the opposition between the transcendental one and many is unsatisfactory for several reasons. First, a privation always expresses a lack. But unity cannot mean deficiency, for loss of unity means loss of being. (...) Second, Thomas himself emphatizes that unity does not remove multitude but division, and that the notions of multitude and division are not identical», J. A. AERTSEN, Medieval philosophy and the transcendentals. The case of Thomas Aquinas, E. J. Brill, 1926, pp. 229-230. 
comporta privación en uno de sus miembros. Mas ya que el propio Aristóteles afirma en ese texto que la oposición de lo uno y lo múltiple es de contrariedad y no de ninguna otra clase, habremos de entender que la privación comportada por lo uno (en tanto que es in-diviso) no posee la índole de la privación pura o estrictamente dicha. Basta advertir que no es eventual o contingente la in-división -la falta de multiplicidad intrínseca- de lo uno qua uno, y que lo múltiple no carece de toda forma o tipo de unidad, como quiera que, si de ningún modo fuese uno, carecería enteramente de ser: no tendría ninguna realidad.

¿Qué podría ser, en el más amplio sentido en que del ser cabe hablar, lo enteramente desprovisto de la índole de lo uno, es decir, lo enteramente dividido de sí mismo? -Sólo es válida una respuesta a esta pregunta: a saber, lo que en sí mismo no tiene unidad alguna, o sea, lo intrínsecamente múltiple, es quiddidad paradójica, y ello por dos razones: $1^{a}$. porque no cabe que lo intrínsecamente múltiple tenga esencia alguna, dado que toda esencia co-implica el correspondiente acto de ser, y este acto no puede darse en lo enteramente falto de unidad; $2^{a}$. porque la quiddidad de lo meramente posible no está intrínsecamente dividida, y las quiddidades divididas en sí o contra sí mismas son intrínsecamente contradictorias: esto es, paradójicas. La sirena, el círculo cuadrado, el centauro, el hierro de madera, etc. son quiddidades en sí o contra sí mismas divididas, no quiddidades de lo meramente posible.

Sostener, como sin duda puede hacerse, que las quiddidades intrínsecamente divididas son inconcebibles es caer en contradicción. No podemos negarnos la posibilidad de concebirlas sin que estemos eo ipso concibiéndolas. ¿Cómo podríamos negar lo no pensado en modo alguno por nosotros? El concepto de lo imposible es un concepto posible, tanto como el concepto de la nada, el cual no es una nada de concepto. Mas con esta comparación no pretendo afirmar que el concepto de lo imposible sea idéntico al concepto de la nada, ni que la nada sea conceptualmente idéntica a las quiddidades paradójicas o intrínsecamente divididas. Veámoslo, de un modo más explícito, en la siguiente serie de proposiciones:

a)

1) El concepto de lo imposible es idéntico al concepto de la nada.

2) La proposición 1) es falsa (porque la idea de la nada es el concepto de lo que no tiene ser, mientras que la idea de lo imposible es el concepto de lo que no puede ser; y así la idea de la nada no es el concepto de la sirena, ni el del círculo cuadrado, ni el del hierro de madera, etc.); 
3) La nada no puede tener ser;

4) La proposición 3) es verdadera (porque, de lo contrario, la nada sería uno de los entes posibles);

5) La nada es lo único que no puede tener ser;

6) La proposición 5) es falsa (porque tampoco pueden tener ser las quiddidades intrínsecamente divididas).

b)

7) La nada es conceptualmente idéntica a las quiddidades paradójicas;

8) La proposición 7) es falsa (porque la comprensión de la idea de la nada no tiene dos características o notas recíprocamente incompatibles en un mismo sujeto);

9) La proposición 8) es verdadera;

10) La proposición 9) es verdadera (porque no cabe que dos proposiciones contradictorias entre sí sean ambas verdaderas, ni que las dos sean falsas, y por que es falsa la proposición 7), dado que la 8) es verdadera);

11) La proposición 10) no puede ser falsa;

12) La proposición 11) no puede ser verdadera.

$$
* * *
$$

La oposición de lo uno y lo múltiple exige, si es de contrariedad, que sus dos polos convengan en pertenecer al mismo género. Contraria sunt eiusdem generis. Ahora bien, aunque lo uno y lo múltiple coinciden en tener realidad, por lo cual la índole de ente se les puede y debe atribuir, ha de tenerse, sin embargo, en cuenta que el ente no es ningún género, sino lo que ante todo pertenece al orden trascendental. Por consiguiente, si la afirmación contraria sunt eiusdem generis es aceptada sin ninguna reserva ni matiz, será menester negar que lo uno y lo múltiple se opongan tal como se oponen los contrarios. Mas si bien esta conclusión es intachable, no se debe olvidar que su validez comporta la hipótesis de la afirmación, sin ningún matiz o reserva, de la pertenencia de los contrarios a uno y el mismo género. Literalmente tomada, la afirmación de esta pertenencia es válida dentro del orden de lo categorial, que es también donde únicamente puede hablarse del «género» en su estricta y propia acepción. Por el contrario, en el orden trascendental lo común no puede ser género en esa acepción estricta y propia. Es verdad que todo lo que es género es común, mas no es verdad que todo lo que es común sea género. Por debajo y por encima del género están, sin dejar de ser a su manera algo común, respectivamente la especie y lo trascendental. Y así como a la especie cabe 
llamarla simplemente género (tal como ocurre en el género próximo), así también a lo trascendental, $y$ ante todo al ente, cabe llamarlo género de una manera impropia, en el sentido de que es algo común, como asimismo, aunque de otra manera y en un nivel lógico más bajo, es algo común la especie.

Lo decisivo para que sea válida la afirmación de la contrariedad de lo uno y lo múltiple es que hay algo común a ellos, y ese algo común es el carácter propio de lo real, el tener efectivo ser o, lo que es lo mismo, la posesión de la índole de los auténticos entes. La proposición contraria sunt eiusdem generis vale, sin ningún matiz o reserva, en el orden categorial (expresamente en el caso de las cualidades, aunque no en todas). Fuera del orden categorial, la proposición válida para la oposición de los contrarios podría formularse así: contraria sunt eiusdem communis transcendentalis, o bien con otro giro equivalente. 